\title{
Contribution of antimicrobial photo- sonodynamic therapy in wound healing: an in vivo effect of curcumin-nisin-based poly (L-lactic acid) nanoparticle on Acinetobacter baumannii biofilms
}

\author{
Maryam Pourhajibagher ${ }^{1}$, Babak Pourakbari ${ }^{2,3}$ and Abbas Bahador ${ }^{4,5^{*}}$
}

\begin{abstract}
Background: The biofilm-forming ability of Acinetobacter baumannii in the burn wound is clinically problematic due to the development of antibiotic-resistant characteristics, leading to new approaches for treatment being needed. In this study, antimicrobial photo-sonodynamic therapy (aPSDT) was used to assess the anti-biofilm efficacy and wound healing activity in mice with established A. baumannii infections.

Methods: Following synthesis and confirmation of Curcumin-Nisin-based poly (L-lactic acid) nanoparticle (CurNisNp), its cytotoxic and release times were evaluated. After determination of the sub-significant reduction (SSR) doses of CurNisNp, irradiation time of light, and ultrasound intensity against A. baumannii, anti-biofilm activity and the intracellular reactive oxygen species (ROS) generation were evaluated. The antibacterial and anti-virulence effects, as well as, histopathological examination of the burn wound sites of treated mice by CurNisNp-mediated aPSDT ${ }^{\text {SSR }}$ were assessed and compared with silver sulfadiazine (SSD) as the standard treatment group.

Results: The results showed that non-cytotoxic CurNisNp has a homogeneous surface and a sphere-shaped vesicle with continuous release until the 14th day. The dose-dependent reduction in cell viability of A. baumannii was achieved by increasing the concentrations of CurNis Np, irradiation time of light, and ultrasound intensity. There was a time-dependent reduction in biofilm growth, changes in gene expression, and promotion in wound healing by the acceleration of skin re-epithelialization in mice. Not only there was no significant difference between aPSDTSSR and SSD groups in antibacterial and anti-virulence activities, but also wound healing and re-epithelialization occurred more efficiently in aPSDT ${ }^{S S R}$ than in the SSD group.
\end{abstract}

Conclusions: In conclusion, CurNisNp-mediated aPSDT might be a promising complementary approach to treat burn wound infections.

Keywords: Antimicrobial photodynamic therapy, Antimicrobial sonodynamic therapy, Biofilms, Burn wound infection, Curcumin, Nisin, Silver sulfadiazine

*Correspondence: abahador@sina.tums.ac.ir

${ }^{5}$ Fellowship in Clinical Laboratory Sciences, BioHealth Lab, Tehran, Iran

Full list of author information is available at the end of the article

\section{Background}

Burn wound infection is one of the common and serious healthcare problems [1]. Many factors such as type, amount of the microbial burden colonizing in burn 
wounds, as well as, the ability of microbial biofilm formation are the risk factors in morbidity and mortality in burn patients [2]. Burn wounds are colonized by Grampositive bacteria derived from skin commensals, followed later by Gram-negative bacteria and yeasts [3]. Acinetobacter baumannii is an important opportunistic bacterium capable of developing a wide range of infections in burn wounds [4]. It emerged as the common and invasive bacteria under its robust antibacterial resistance and virulence factor. The inappropriate over use of antibiotics in empirical therapy led to multidrug-resistant $A$. baumannii outbreaks all over the world $[5,6]$. Therefore, a key challenge is to find new non-antibiotic therapies to eliminate $A$. baumannii from colonizing in burn wounds.

A. baumannii senses light through the photoreceptor protein "blue light sensing A", which is encoded by the $b l s A$ gene. $b l s A$ expression prevents the formation of biofilm as one of the most important virulence factors and ultimately leads to increased susceptibility of bacteria to antimicrobial agents. The involvement of CsuE (csuE) and AbaI (abaI) proteins in the biofilm formation of $A$. baumannii is well-established. CsuE as one of the main A. baumannii adhesions involved in initial attachment as the first step for colonization and subsequent biofilm formation. AbaI, is an essential factor for production of the acyl-homoserine lactone signal, which plays critical role in biofilm development. The loss of functional csuE and abaI activities in A. baumannii are corresponding decrease in growth and biofilm formation rate in softtissue infection [7].

Recently, it was reported that curcumin-nisin (CurNis) formulation is a non-toxic compound with antimicrobial and anti-inflammatory activities [8]. Nisin as an antimicrobial peptide can be used synergistically in combination with conventional therapeutic agents and activate the adaptive immune response and have an immunomodulatory role. Also, the potential for using nisin to treat local site-specific infections such as skin infections has been reported [9]. Curcumin, a natural polyphenol compound derived from the turmeric rhizomes (Curcuma longa L.), through its polyphenol nature and the presence of methoxy and hydroxyl groups, is attributed to many properties, in particular antioxidant, anti-inflammatory, antimicrobial, antimutagenic, and anti-angiogenic ones $[10,11]$. The great potential effects of curcumin against chronic diseases including irritable bowel syndrome (IBS) and renal protection from high doses of naproxen in the rat model are due to its antioxidant and anti-inflammatory activities [12]. There is one meta-analysis based on randomized clinical trials, performed by Jakubczyk et al. $[11,12]$, describing an intervention of pure curcumin, which increased total antioxidant capacity $(\mathrm{SMD}=2.696$, $\mathrm{Z}=2.003, \mathrm{CI}=95 \%, p=0.045)$. Despite the therapeutic uses of these compounds, they have a short half-life, poor pharmacokinetics, poor bioavailability, low solubility, and instability, which limits their therapeutic effect in vivo [13]. Therefore, using a biodegradable polymer such as poly (L-lactic acid) for the development of nanocarrier can promote their effective therapeutic usage [14].

Studies also showed that Cur has significant antimicrobial effects at very low molarity following activation by light and/or ultrasound in the process of antimicrobial photodynamic therapy (aPDT) and antimicrobial sonodynamic therapy (aSDT) [13, 15-19]. aPDT is a potential alternative approach, which is the photoinactivation of microorganisms and thereby kill cells by reactive oxygen species (ROS) generated by a harmless visible light-activated nontoxic photosensitizer in the presence of oxygen. According to the literature, aPDT has antimicrobial effects on bacteria isolated from infected human burn wounds and improves wound healing in mice and humans [20-23]. Sun et al. reported aPDT may be an appropriate alternative to standard therapies for infected wounds [24]. aSDT, as a novel ultrasound-driven treatment has been found to be very effective in killing microorganisms due to its strong penetrating power through a sonochemical process [17]. Several recent reports have mentioned satisfactory results with aSDT in inhibiting microorganisms due to its non-invasive nature [17, $18,25]$. The main advantage of aSDT over aPDT is the increased penetration of ultrasound irradiation to the target site compared to light [17]. aPDT and aSDT are the local therapies and can reduce side effects of systemic administration of antimicrobial agents. Another advance in aPDT and aSDT is the management of multidrugresistant bacterial infections and the produced ROS by them cause broad-spectrum oxidative damage to the target cells Interestingly, aPDT and aSDT are promising strategies to which to date no resistant strain has been reported [18, 25].

It has been shown that silver sulfadiazine (SSD) is an effective topical antibiotic for treatment and protect of second-degree (partial-thickness) and third-degree (fullthickness) burns, respectively, which should be apply for several consecutive days [26]. Along with the beneficial antimicrobial properties of SSD, its major disadvantage is release of silver $(\mathrm{Ag}+)$ ions in high doses and the toxic effects on keratinocytes and fibroblasts [27]. Due to the increasing need for the effective treatment of burn wound infections, more attention in this study has been focused on the simultaneous use of aPDT and aSDT, which is called antimicrobial photo-sonodynamic therapy (aPSDT). Herein, we explored the anti-biofilm efficacy of aPSDT using CurNis-based poly (L-lactic acid) nanoparticles (CurNisNp) as a photo-sonosensitizer to eliminate the biofilms of $A$. baumannii on surfaces of wounds in the 
animal model. It was hypothesized that CurNisNp-mediated aPSDT will remove the $A$. baumannii biofilms and improve wound healing more than aPDT and/or aSDT and provide an experimental basis for future clinical application in the treatment of burn wound infections.

\section{Results}

\section{Confirmation of synthesized CurNisNp}

Surface morphology of synthesized CurNis in nano scale was confirmed using FESEM analysis. As shown in Fig. 1a, the surface of CurNisNp appeared to be homogeneous with a spherical shape indicating acceptable compatibility between Cur-Nis and poly (L-lactic acid). The average diameter, PDI, and zeta potential of CurNisNp were approximately $78.6 \pm 17.9 \mathrm{~nm}$, $0.171 \pm 0.04$, and $-30.7 \pm 4.84 \mathrm{mV}$, respectively (Fig. $1 \mathrm{~b}$, c). Ultraviolet-Visible (UV-Vis) spectra of pure Cur, Nis, and CurNisNp are presented in Fig. 1d. Accordingly, the absorption spectra of synthesized CurNisNp showed an absorbance peak at $439 \mathrm{~nm}$.

\section{In vitro drug release}

Standard plot obtained from UV-absorbance analysis of free Cur-Nis was used to estimate from the release kinetics of CurNis-entrapped nanoparticle. In vitro release of CurNis from CurNisNp showed a rapid initial burst at the first hour followed by a sustained release for 14 days. Around $20-40 \%$ of the total entrapped CurNis was released within $10 \mathrm{~h}$ and around $80 \%$ was released at 4 days. This in vitro release profile showed that continuous release of CurNis was continued until the 14th day (Fig. 2).

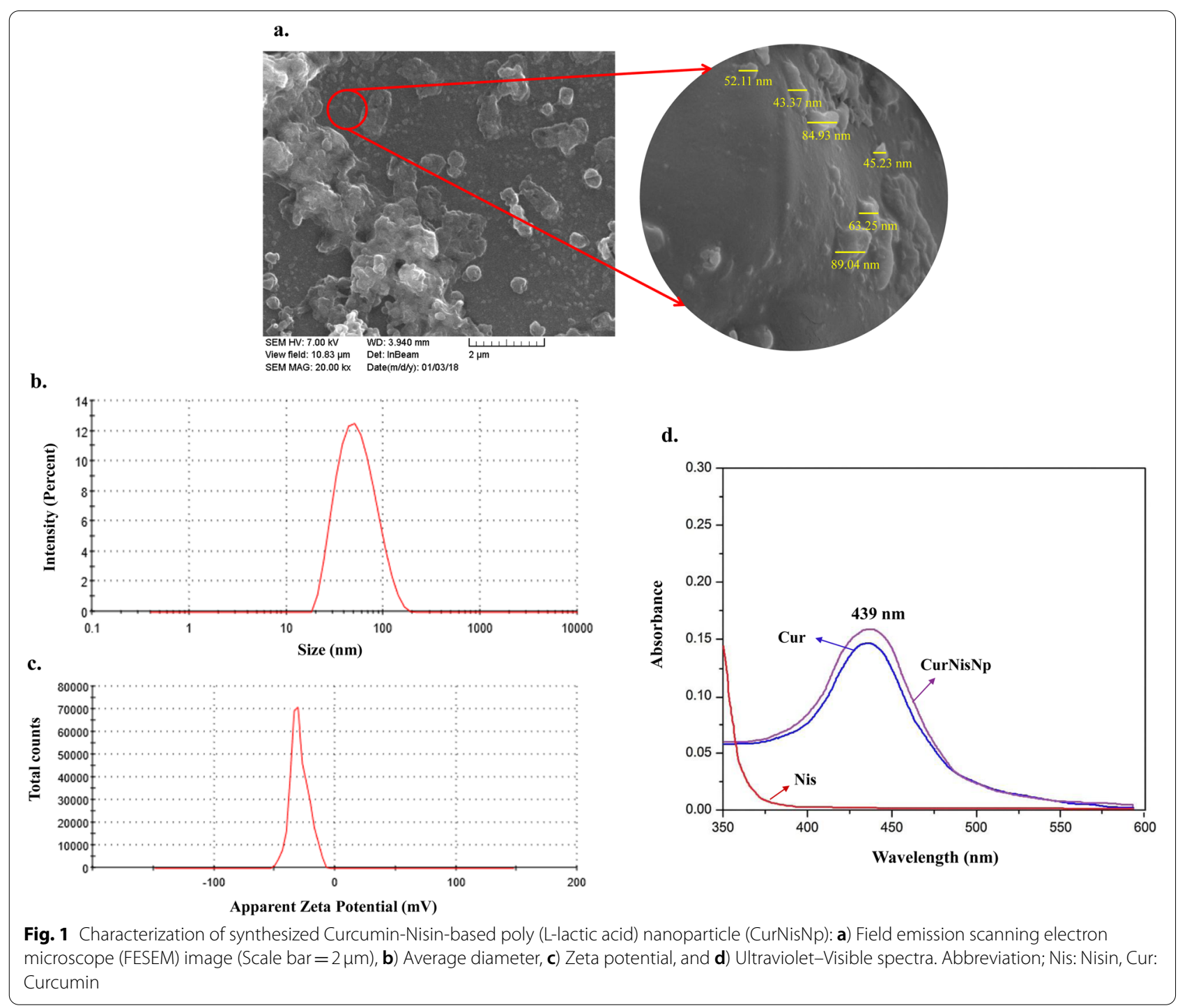




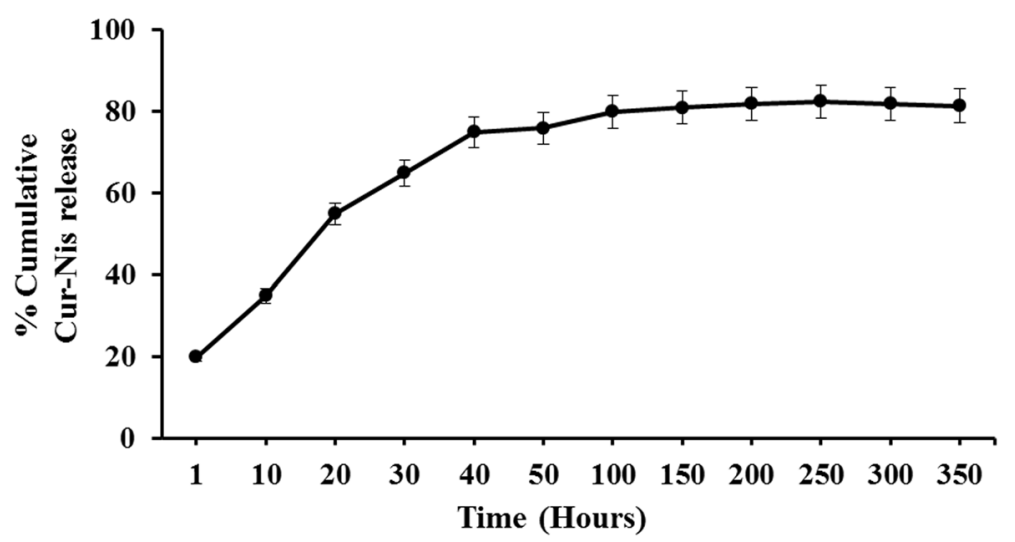

Fig. 2 In vitro drug release of Curcumin-Nisin (Cur-Nis) from Curcumin-Nisin-based poly (L-lactic acid) nanoparticle (CurNisNp) during 14 days

\section{Cytotoxicity assessment of CurNisNp on normal human} skin fibroblast cell line (MHFB-1) cells

Cytotoxicity analysis using MTT assay kit demonstrated that CurNisNp at the highest concentration $(500 \mu \mathrm{g} / \mathrm{mL})$ was not significantly toxic to MHFB-1 (Fig. 3a). In the flow cytometry assay shown in Fig. 3b, the cell apoptosis rate was very negligible. Acridine orange $(\mathrm{AO})$ and ethidium bromide (EB) fluorescent staining is a method to analyze the viable cells, early apoptosis, and late apoptosis, as well as the morphologic changes in cells. As the results shown, untreated and treated MHFB-1 cells showed viable cells with green color and intact nuclei
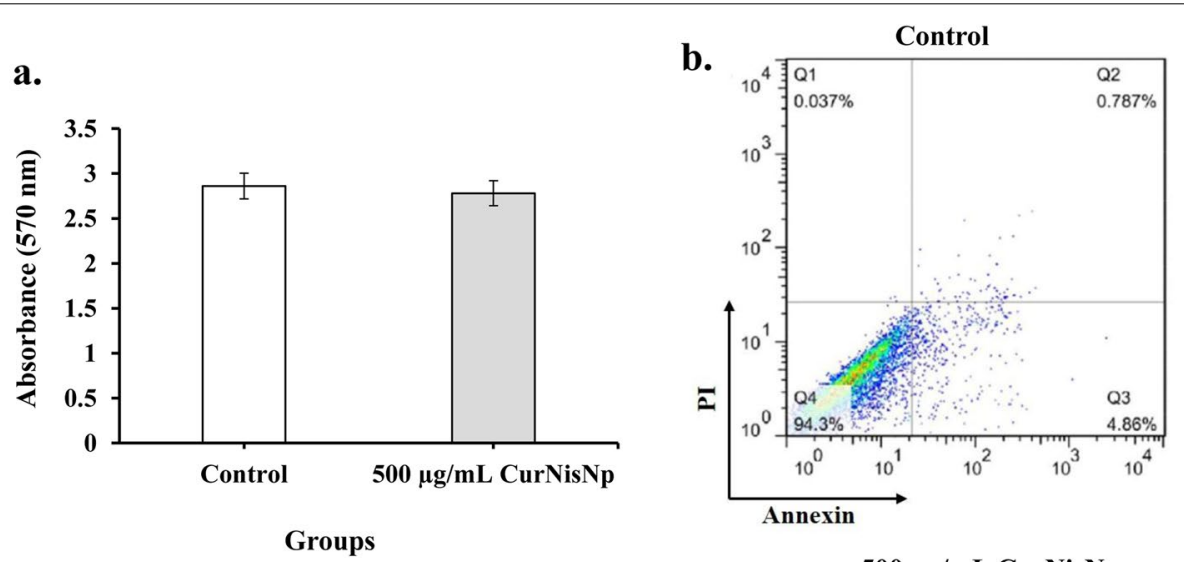

c.

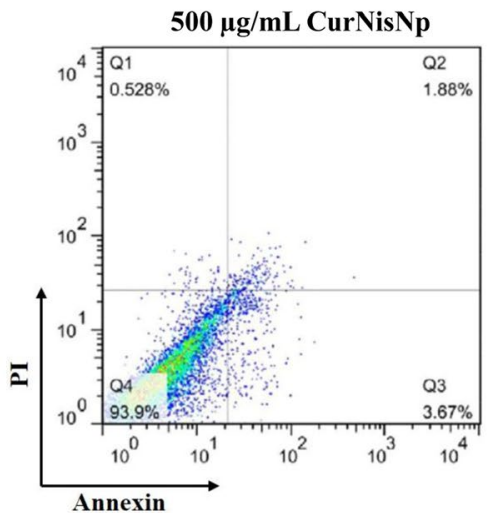

Fig. 3 Cytotoxic effects of Curcumin-Nisin-based poly (L-lactic acid) nanoparticle (CurNisNp) on cell viability of normal human skin fibroblast cell line (MHFB-1): a) MTT assay, b) Annexin V-FITC/Propidium iodide (PI) staining detected by flow cytometry, and c) Fluorescent micrograph of acridine orange $(\mathrm{AO})$ and ethidium bromide (EB) staining of cells 
(Fig. 3c). Taken together, these data demonstrate that CurNisNp had no cytotoxic effect on cells.

\section{SSR doses of CurNisNp, irradiation time of LED,} and ultrasound intensity against $A$. baumannii

The microbroth dilution assay were performed to detect the SSR dose of CurNisNp (CurNisNp ${ }^{\text {SSR }}$ ) against $A$. baumannii. The data indicate that the dose-dependent reduction in cell viability was induced by increasing the concentrations of CurNisNp. When 31.2 to $500 \mu \mathrm{g} / \mathrm{mL}$ CurNisNp were used, the cell viability of $A$. baumannii significantly decreased compared to the control group $(P<0.05)$, whereas there was no remarkable reduction when CurNisNp was decreased from 15.6 to $0.9 \mu \mathrm{g} / \mathrm{mL}(P>0.05)$. So, the maximum CurNisNp ${ }^{\text {SSR }}$ against $A$. baumannii was found to be $15.6 \mu \mathrm{g} / \mathrm{mL}$ with the median (interquartile range [IQR]) $\log _{10} \mathrm{CFU} / \mathrm{mL}$ of 7.1 (6.8-8.9) (Fig. 4a).

Also, the cell viability of $A$. baumannii was decreased with the enhancement of irradiation time of LED and irradiation intensity of ultrasound waves. The $\log _{10}$ $\mathrm{CFU} / \mathrm{mL}$ reductions in cell viability of $A$. baumannii were demonstrated at ultrasound intensity of 53.4 and $61.6 \mathrm{~mW} / \mathrm{cm}^{2}$, respectively $(P<0.05)$. Additionally, there was a significant decrease in $A$. baumannii cell viability following exposure to LED with the energy density of
$300-420 \mathrm{~J} / \mathrm{cm}^{2}$ for $5 \mathrm{~min}(\mathrm{P}<0.05)$. Taking into account the cell survival rate, the maximum SSR doses of irradiation time of LED (LED ${ }^{\mathrm{SSR}}$ ) and irradiation intensity of ultrasound waves (US ${ }^{\mathrm{SSR}}$ ) were $4 \mathrm{~min}$ (energy density of $\left.252-336 \mathrm{~J} / \mathrm{cm}^{2}\right)$ and $45.2 \mathrm{~mW} / \mathrm{cm}^{2}$, respectively $(P>0.05)$ with the median (IQR) $\log _{10} \mathrm{CFU} / \mathrm{mL}$ of $7.4(6.9-8.6)$ and 8.3 (7.1-9.4), respectively (Fig. 4b, c).

\section{Antimicrobial effects of CurNisNp, LED irradiation, ultrasound waves, and their combination against $A$. baumannii in planktonic growth}

The results in Fig. 5 showed that all treatment groups could decrease the cell viability of $A$. baumannii in planktonic growth compared with the control group $(P<0.05)$. As shown in Fig. 5 , the median (IQR) $\log _{10} \mathrm{CFU} / \mathrm{mL}$ of CurNisNp${ }^{\text {SSR }}$ plus LED ${ }^{\text {SSR }}$, CurNisNp ${ }^{\text {SSR }}$ plus US ${ }^{\text {SSR }}$, LED ${ }^{\text {SSR }}$ plus LED ${ }^{\text {SSR }}$, and CurNisNp ${ }^{\text {SSR }}$ plus LED ${ }^{\text {SSR }}$ plus US $^{\text {SSR }}$ were 6.2 (4.8-7.1), 5.4 (4.5-7.1), 6.8 (5.2-7.6), and 3.7 (2.9-5.1), respectively.

\section{Anti-biofilm effects of treatment groups against $A$. baumannii}

Anti-biofilm activities of different treatment groups against $A$. baumannii were determined using colorimetric assay. The anti-biofilm activity of different

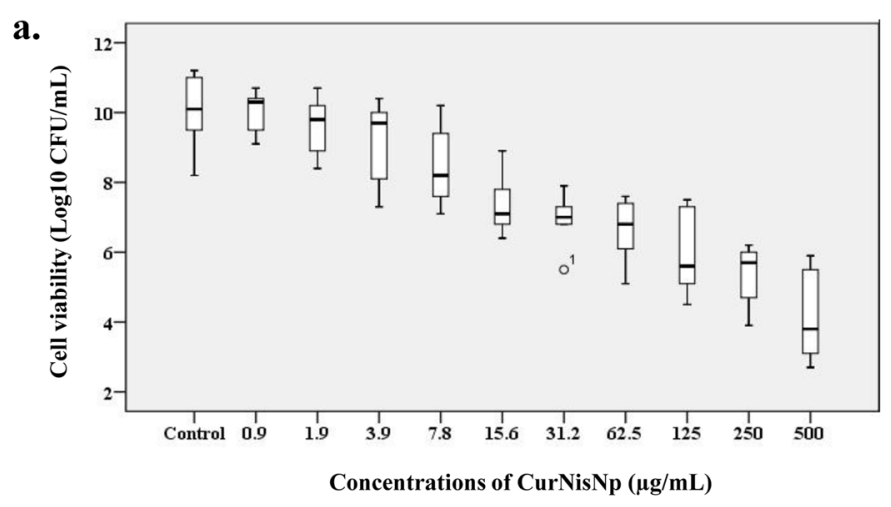

b.

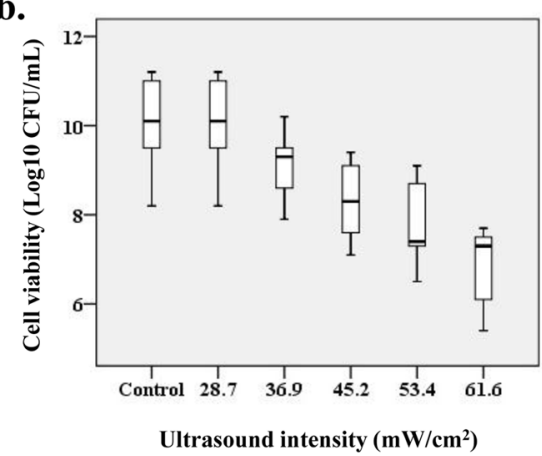

c.

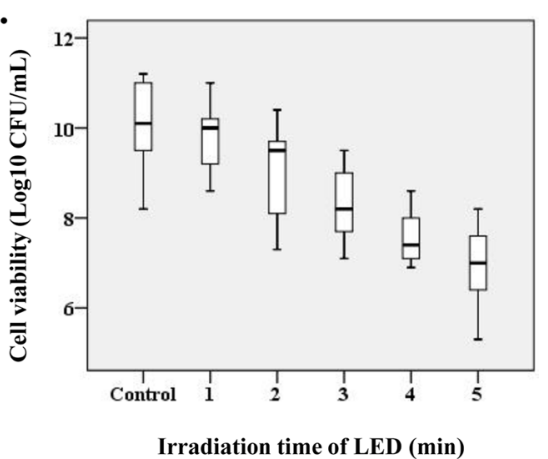

Fig. 4 Cell viability of A. baumannii in different treatment groups: a) Curcumin-Nisin-based poly (L-lactic acid) nanoparticle (CurNisNp), b) Ultrasound intensity, and c) Irradiation time of light emitting diode (LED) 


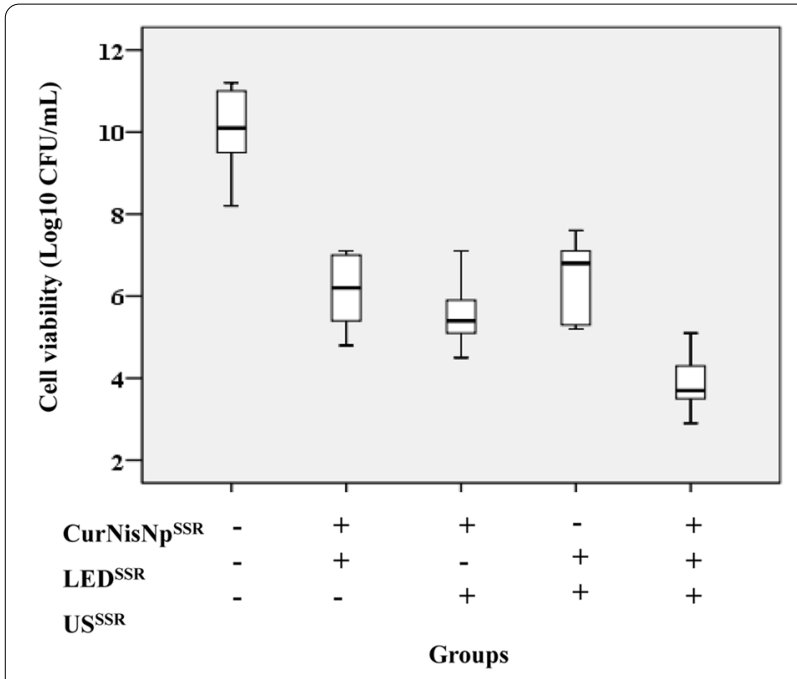

Fig. 5 Cell viability of A. baumannii following treatment with sub-significant reduction doses of Curcumin-Nisin-based poly (L-lactic acid) nanoparticle (CurNisNp ${ }^{\text {SSR }}$ ), ultrasound intensity (US ${ }^{\text {SSR }}$, and Irradiation time of light emitting diode (LED $\left.{ }^{S S R}\right)$

Table 1 Anti-biofilm effects of different treatment groups against $A$. baumannii biofilms

\begin{tabular}{|c|c|c|c|c|}
\hline Groups & $\begin{array}{l}\text { Mean } \pm S D \text { of } \\
O D \text { at } 570 \mathrm{~nm}\end{array}$ & $\begin{array}{l}\text { Median (IQR) } \\
\text { of OD at } \\
570 \mathrm{~nm}\end{array}$ & $\begin{array}{l}\text { Reduction } \\
\text { of OD (\%) }\end{array}$ & $P$ value \\
\hline Control & $3.26 \pm 0.088$ & $3.28(3.15-3.36)$ & - & - \\
\hline LED $^{\text {SSR }}$ & $2.76 \pm 0.144$ & $2.73(2.61-2.93)$ & 15.3 & 0.000 \\
\hline$U^{S S R}$ & $2.60 \pm 0.070$ & $2.57(2.53-2.70)$ & 20.2 & 0.000 \\
\hline CurNisNp ${ }^{S S R}$ & $2.52 \pm 0.066$ & $2.53(2.43-2.61)$ & 22.5 & 0.000 \\
\hline $\begin{array}{l}\text { CurNisNp- } \\
\text { aPDT }\end{array}$ & $0.93 \pm 0.079$ & $0.91(0.85-1.05)$ & 71.4 & 0.000 \\
\hline SSD & $0.80 \pm 0.141$ & $0.76(0.65-1.00)$ & 75.3 & 0.000 \\
\hline $\begin{array}{l}\text { CurNisNp- } \\
\text { aSDT }^{\text {SSR }}\end{array}$ & $0.75 \pm 0.105$ & $0.78(0.68-0.96)$ & 76.8 & 0.000 \\
\hline $\begin{array}{l}\text { CurNisNp- } \\
\text { aPSDT }\end{array}$ & $0.20 \pm 0.058$ & $0.21(0.13-0.26)$ & 93.6 & 0.000 \\
\hline
\end{tabular}

treatment groups was evaluated by colorimetric assay. The mean \pm standard deviation (SD) and median (IQR) of $\mathrm{OD}$ value of $A$. baumannii biofilm following the different treatments are presented in Table 1. All the aPDT $^{\text {SSR }}$, aSDT ${ }^{\text {SSR }}$, and aPSDT ${ }^{\text {SSR }}$ groups based on CurNisNp had anti-biofilm effects against $A$. baumannii and could considerably reduce the bacterial counts in biofilm structures in comparison with the control group $(P<0.05)$. CurNisNp-aPSDT ${ }^{\text {SSR }}$ showed a significantly higher anti-biofilm activity than the other treatment groups $(\mathrm{P}<0.05)$. Although the biofilms of $A$. baumannii are displayed to be more susceptible to CurNisNpaSDT $^{\text {SSR }}$ than CurNisNp-aPDT ${ }^{\text {SSR }}$, this difference is not significant $(P>0.05)$. According to the results in Table 1 , although there is no significant difference in the reduction of biofilm between the SSD group with CurNisNp$\operatorname{aPDT}^{\mathrm{SSR}}(P=0.129)$ and CurNisNp-aSDT ${ }^{\mathrm{SSR}}(P=0.968)$, but CurNisNp-aPSDT ${ }^{\text {SSR }}$ compared to SSD was able to significantly reduce the $A$. baumannii biofilm $(P=0.001)$.

\section{Intracellular ROS generation}

To investigate whether ROS is involved in aPDT and aSDTinduced antimicrobial effect, the levels of intracellular ROS generation in treated A. baumannii cells were assessed. A. baumannii cells when incubated in presence in CurNisNp alone and SSD, showed no remarkable ROS generation (2.3-fold and 0.2-fold, respectively; $P>0.05$ ), while, a significant ROS production was observed when cells were treated by CurNisNp and irradiated with ultrasound waves (13.7-fold; $P<0.05)$ and LED (15.2-fold; $\mathrm{P}<0.05)$. Also, no considerable ROS generation was observed when cells were exposed to aPDT and aSDT $(\mathrm{P}>0.05)$.

\section{In vivo assessment of wound healing}

Wound healing process and the percentage of wound contracture rate was shown in Fig. 6. By day 5, all groups showed thick scabs. After day 10, wound healing was accelerated with application of aPSDT ${ }^{\text {SSR }}$ compared to SSD and control groups. As shown in Fig. 6, aPSDT ${ }^{\text {SSR }}$ significantly enhanced wound closure and re-epithelialization during burn wound healing process $(P<0.05)$. On day 14, the wound surfaces were almost closed and wound sizes were smallest in aPSDT ${ }^{\text {SSR }}$ groups.

\section{In vivo antibacterial effects of CurNisNp-mediated aPSDT on infections of burn wounds}

We used mouse, a well-known burn wound model, to explore the antibacterial effects of CurNisNp-mediated aPSDT. In this study, the antibacterial effects of aPSDT ${ }^{\text {SSR }}$ and SSD groups were studied on burn wound infections in a mouse model. The results show that the time-dependent reduction in cell viability was induced with the passing of the days. According to the results in Fig. 7, at the 5th, 10th, and 15th days, successful antibacterial effects against treated $A$. baumannii by aPSDT $^{\text {SSR }}$ and SSD were achieved $(P<0.05)$. aPSDT ${ }^{\text {SSR }}$ group could reduce the amount of $A$. baumannii by up to $4.72 \pm 0.15$ $\log _{10} \mathrm{CFU} / \mathrm{mL}$ compared with the no treatment group on the 15th day $(\mathrm{P}<0.05)$, while SSD was able to reduce the amount of bacteria by up to $6.93 \pm 1.30 \log _{10} \mathrm{CFU} / \mathrm{mL}$ in comparison with the control group $(P<0.05)$.

\section{Effects of CurNisNp-mediated aPSDT on virulence gene expression patterns in A. baumannii}

To explore the mechanism underlying the anti-virulence induced by CurNisNp-mediated aPSDT, the 


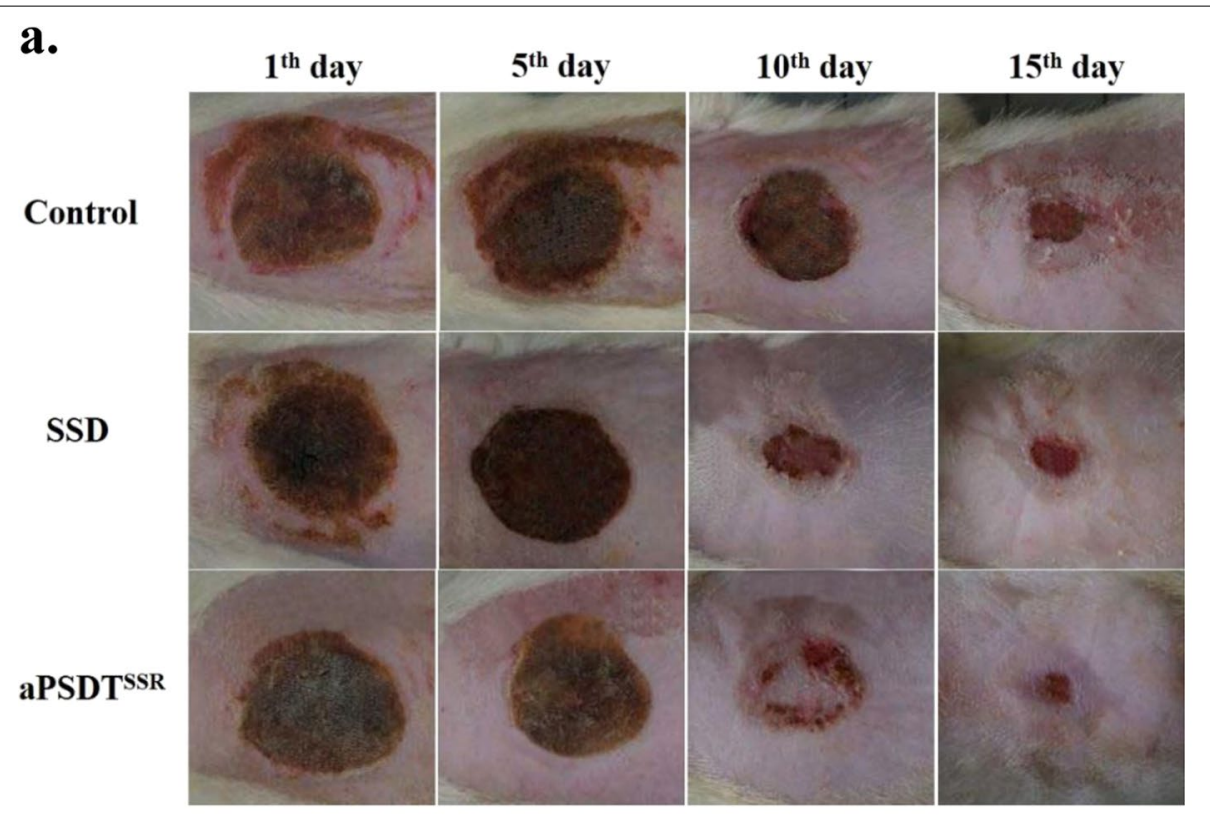

b.

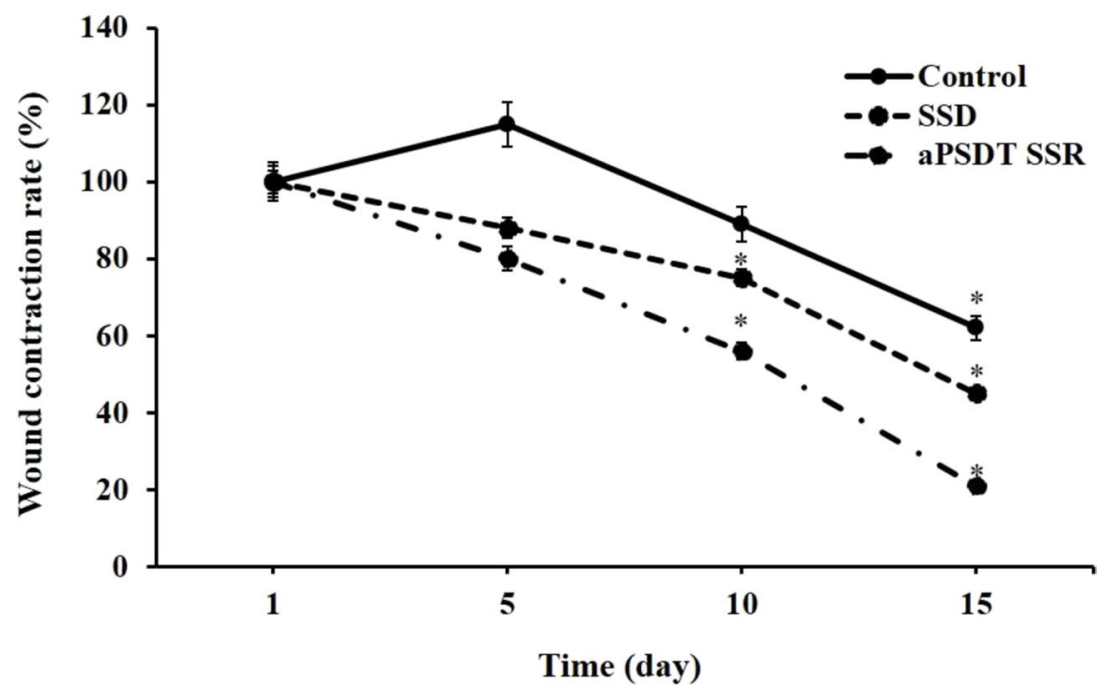

Fig. 6 Wound healing process observation: a) Serial wound healing process on day 1, day 5, day 10, and day 15 under gross observation in CurNisNp at sub-significant reduction dose + Irradiation time of light emitting diode at sub-significant reduction dose + Ultrasound intensity at sub-significant reduction dose (aPSDT ${ }^{S S R}$ ), Silver sulfadiazine (SSD), and no treatment (Control) groups, b) Changes in treated scald wound sizes with CurNisNp at sub-significant reduction dose + Irradiation time of light source at sub-significant reduction dose + Ultrasound intensity at sub-significant reduction dose (aPSDT ${ }^{S S R}$ ), Silver sulfadiazine (SSD), and no treatment (Control) groups on day 1, day 5, day 10, and day 15. $* P<0.05$

gene expression patterns in $A$. baumannii was determined using quantitative real-time PCR. After treatment of $A$. baumannii using aPSDT ${ }^{\text {SSR }}$ and SSD groups, the changes in the expression of virulence genes were evaluated at various time intervals. As shown in Fig. 8, changes in gene expression are time-dependent. In

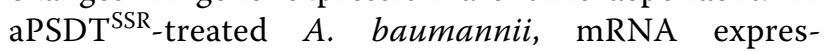
sion was considerably upregulated to 3.1-, 5.4-, 9.6-, and 15.0-folds in blsA on the 1st, 5th, 10th, and 15th days, respectively $(P<0.05)$. In contrast, the expression of genes involved in the formation of microbial biofilm (abaI and csuE) was significantly downregulated $(\mathrm{P}<0.05)$. Also, the change in gene expression in the SSD group was similar to aPSDT ${ }^{\text {SSR }}$ and no significant difference was observed between them $(P>0.05)$. According to the results, a significant reduction in $a b a I$ 


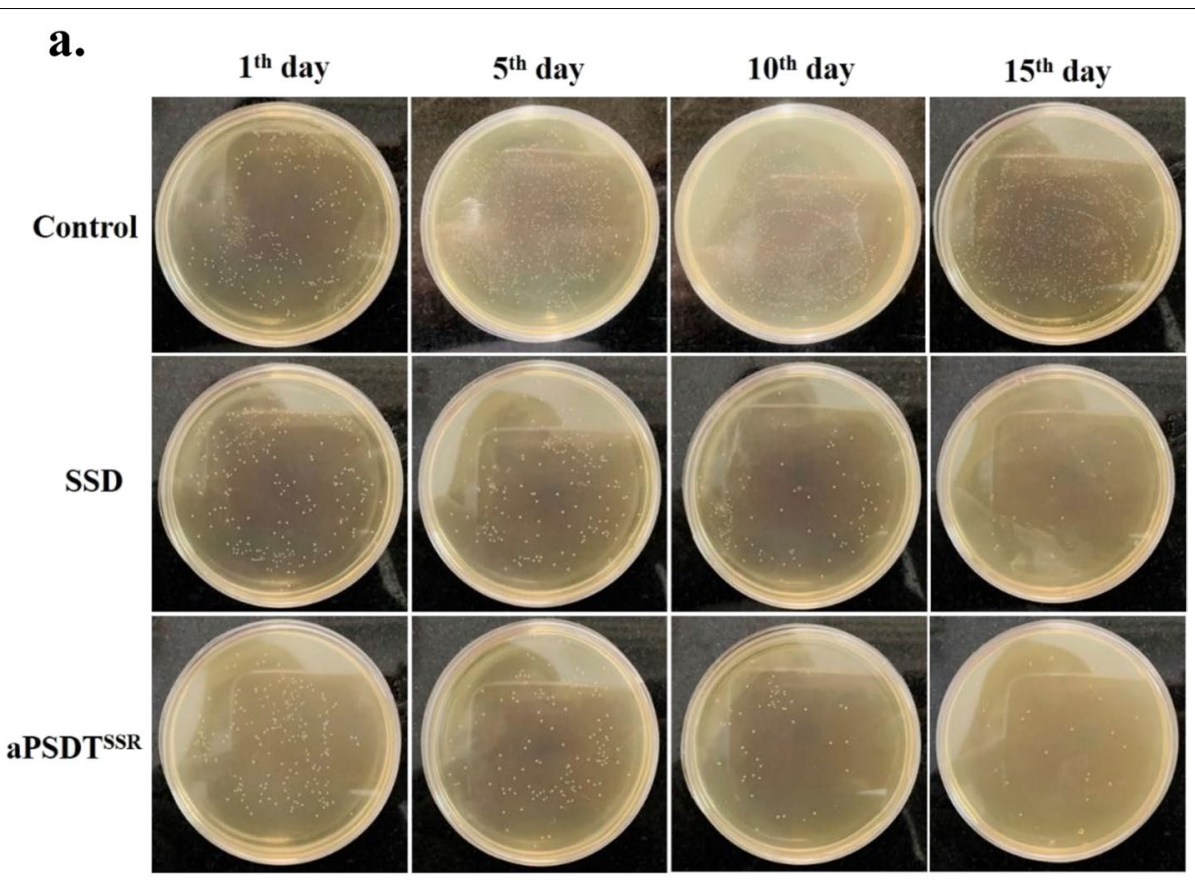

b.

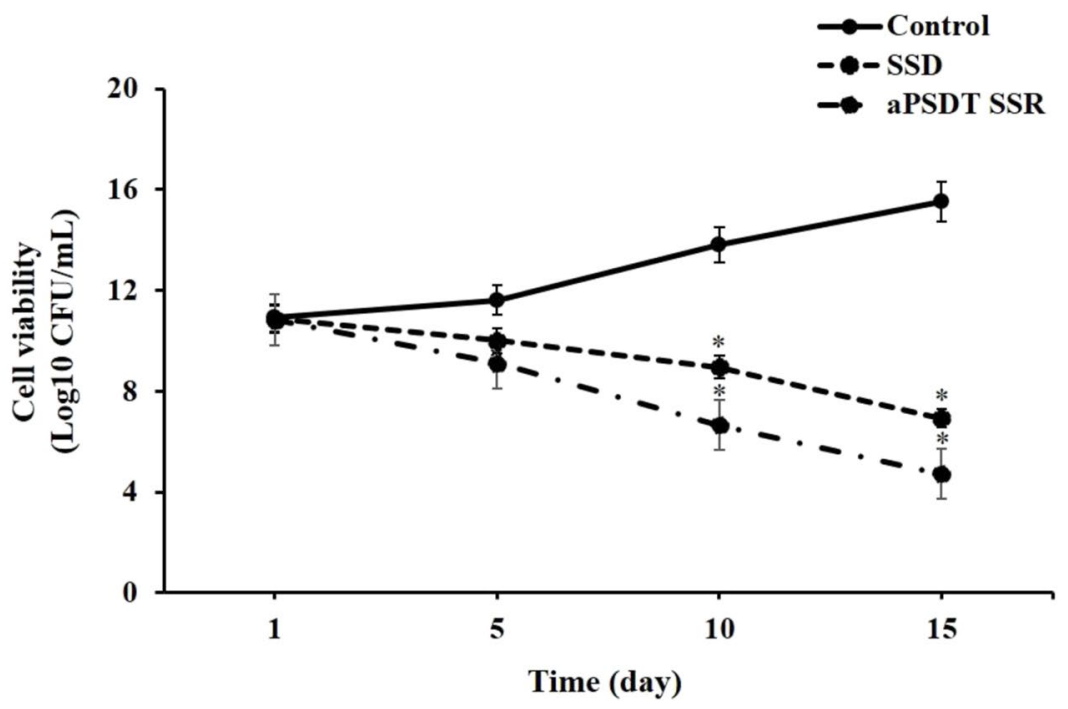

Fig. 7 In vivo antibacterial effects of CurNisNp at sub-significant reduction dose + Irradiation time of light emitting diode at sub-significant reduction dose + Ultrasound intensity at sub-significant reduction dose (aPSDT $\left.{ }^{S S R}\right)$, Silver sulfadiazine (SSD) and no treatment (Control) groups against $A$. baumannii on burn wound: a) Bacterial colonies on the agar plates, b) $\log _{10}$ colony forming unit (CFU)/mL counts of $A$. baumannii. $* P<0.05$

and $c s u E$ expression and a considerable increase in $b l s A$ expression was observed on all test days $(\mathrm{P}<0.05)$.

\section{Histopathological analysis}

To investigate whether CurNisNp are involved in

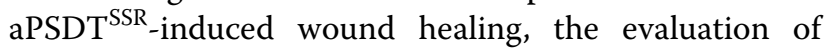
inflammation, fibroblasts, blood vessels, and re-epithelialization in cross-sectioned tissue obtained from each treated burn wound were assessed by the hematoxylineosin (HE) staining under a general optical microscope. Histologically, the dermal inflammatory cell infiltration, abscess formation, absence of collagen distinction, and loss of epidermis were observed in the wounds on 1st day (Fig. 9). The proliferation of marginal epithelium of ulcer was initiated on the 5 th day post aPSDT ${ }^{\text {SSR }}$ and SSD. On 10th day, continuing re-epithelialization was observed in 


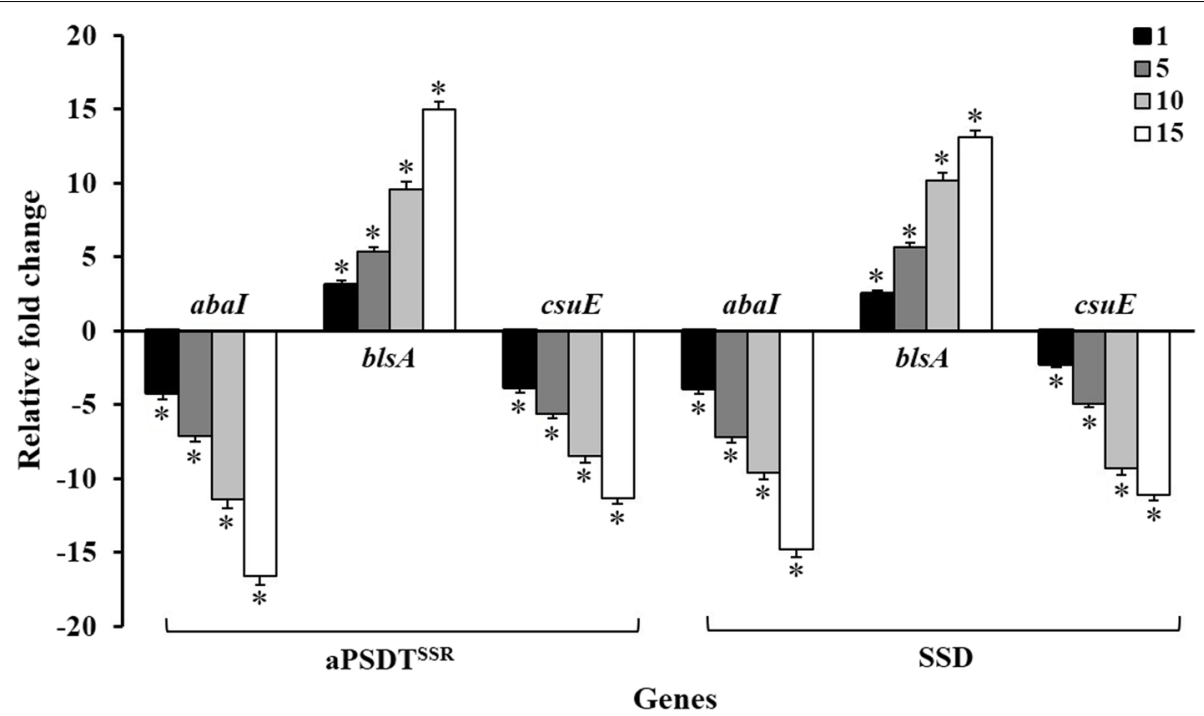

Fig. 8 Relative fold change in mRNA expression level of virulence genes on days 1, 5, 10, and 15 in A. baumannii treated with CurNisNp at sub-significant reduction dose + Irradiation time of light emitting diode at sub-significant reduction dose + Ultrasound intensity at sub-significant reduction dose $\left({ }^{\left(P_{P S D T}\right.}{ }^{\mathrm{SSR}}\right.$ ) and Silver sulfadiazine (SSD) groups. $* \mathrm{P}<0.05$

both aPSDT ${ }^{\text {SSR }}$ and SSD groups compared to the control group. In addition, dermal closure and granulation-tissue formation were initiated. Complete tissue re-epithelialization, fibroblastic proliferation, presence of modeled dense collagen mesh, and moderate fibrosis were the important findings on the 15th day. Day 15 observations suggest that the wound healing effect of $\operatorname{aPSDT}^{\text {SSR }}$ is related to the activation of granulation tissue formation, as well as, collagen regeneration occurred more efficiently in aPSDT ${ }^{\text {SSR }}$ than in the SSD group.

\section{Discussion}

aSDT is analogous to aPDT except that drug activation is obtained via ultrasound instead of light [17]. Similar to aPDT, aSDT process generates ROS through the ultrasound-mediated stimulated sonosensitizer in the

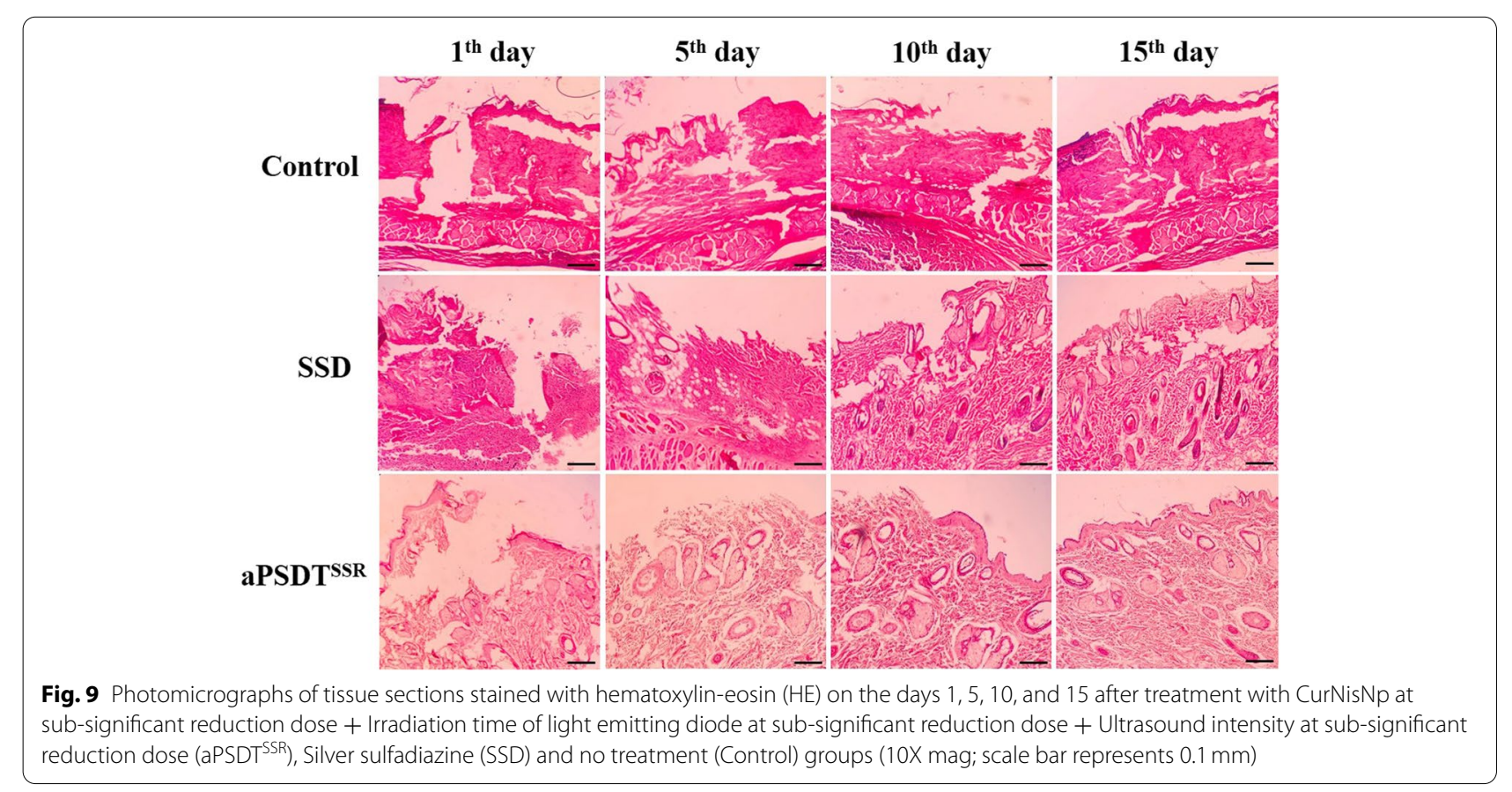


presence of $\mathrm{O}_{2}$ and the ultrasound-activated cavitation effects can destruct the microbial cells [15, 17]. Following the development of the biological activity of aPDT and aSDT in recent years, many sensitizers were found to have both photodynamic and sonodynamic antimicrobial effects. Therefore, aPSDT has been taken into consideration to obtain better treatment outcomes by reducing the dose of both light energy/ultrasound irradiation and sensitizers, in resulting reducing the cytotoxicity effects [28].

An appropriate photo-sonosensitizer should have low toxicity to the host cells and high toxicity to the target cells when associated with ultrasound irradiation and/or illumination. The results of the current study showed that there was negligible cytotoxicity against MHFB-1 cells, suggesting that the synthesized CurNisNp had the least toxicity against eukaryotic cells and good biocompatibility with the host cells.

Recently, the photo-sono-biological and photo-sonokilling potential of Cur has been explored due to its capability of producing ROS, a free radical, and can play a role in intracellular compounds, activating transcription factors, and altering cytokines [15-19]. In this study, poly (L-lactic acid) as a nanocarrier was used to overcome the poor bioavailability of Cur-Nis. poly (L-lactic acid) is one of the most successfully used biodegradable polymers for drug delivery system and produce the non-toxic biodegradable metabolite monomers following its hydrolysis within the body [29]. The obtained CurNisNp was welldispersed in an aqueous solution with a narrow particle size distribution. Additionally, when Cur-Nis is encapsulated in the poly (L-lactic acid), it is segregated from the aqueous phase and can release continuously until 2 weeks $[8,30]$.

Biofilm-related infections are significantly resistant to clearance by the host immune system and various antimicrobial agents [31]. It is evident that biofilm-forming ability can be considered one of the main virulence factors of A. baumannii. Biofilm-producing A. baumannii strains manifest an altered growth rate and transcribe genes that provide them with inherent resistance to living in strict environments, routine antibiotics, and the host immune system $[4,32]$.

The biofilm killing/degradation in vitro was assessed with the colorimetric method based on crystal violate assay. A significant reduction was observed at CurNisNp-mediated aPDT ${ }^{\text {SSR }}$ (71.4\%), aSDT ${ }^{\text {SSR }}(76.8 \%)$, and aPSDT $^{\text {SSR }}$ (93.6\%) when were compared with the control group.

The objective of this study was to determine whether ultrasound irradiation in aSDT can be used to enhance CurNisNp-mediated aPDT to eliminate the microbial biofilms of $A$. baumannii in vitro and in vivo. According to the literature, no studies have been published regarding the concurrent application of aPSDT in eradicating $A$. baumannii biofilms. Although a limited number of studies have evaluated the effect of aPSDT on other microorganisms, their results are consistent with the results of this study [33-36].

The results of Pourhajibagher et al. [33] showed that aPSDT could provide a means of circumventing the limitations of decontamination of the dental implant surfaces. In their ex vivo study, chitosan nanoparticles indocyanine green-mediated aPSDT decreased the polymicrobial periopathogenic biofilms on surfaces of the titanium dental implants to $90.5 \%$. The inactivation of Candida albicans biofilms using combined aPDT/aSDT in oropharyngeal candidiasis was highlighted by Alves et al. [18]. Xu et al. [37] reported that synergistic aPDT and aSDT improved the inhibition rate of antibioticresistant bacteria in infectious diseases compared with either the aPDT or aSDT alone.

During the aPSDT, phot-sonosensitizer attaches to the surface of microbial cells, penetration into the cells, and will be activated by relatively low-intensity ultrasound and visible light irradiation. When phot-sonosensitizertreated microbial cells are received the ultrasound waves in aqueous micro-environments, result in microbubbles and cavitation which implosive collapse of gas-filled microbubbles. After that, released energy can be transferred to the oxygen and generate ROS. On the other hand, the excited photo-sonosensitizer reacts with biomolecules through electron transfer to form radicals, which react with oxygen to generate ROS (Type I); and/ or react directly with oxygen through energy transfer, generating singlet oxygen (Type II). The present data provide indirect evidence that one of the mechanisms of aPSDT is probably based on induction of ROS production and this will result in target-cell death [4, 36, 38-40].

Several studies confirmed that the intracellular ROS production was greatly increased in aPDT and/or aSDT compared with the ultrasound, light, and photosensitizer/or sonosensitizer alone [41-45]. We evaluated intracellular ROS generation by DCFH-DA fluorescence and showed revealed CurNisNp can be activated using both ultrasound and light to produce more ROS for aPSDT against $A$. baumannii biofilms. Moreover, ROS generation was greatly increased in aPSDT ${ }^{\text {SSR }}$ compared with $\mathrm{aPDT}^{\mathrm{SSR}}$ and $\mathrm{aSDT}{ }^{\mathrm{SSR}}$.

The relationship between biofilm formation and related genes was evaluated previously [46]. In this study, we also compared the levels of virulence-associated genes expression such as $b l s A, a b a I$, and $c s u E$ in treated $A$. baumannii by aPDT ${ }^{\mathrm{SSR}}$, aSDT ${ }^{\mathrm{SS}} \mathrm{R}$, and aPSDT $^{\mathrm{SSR}}$. The evidence obtained suggests that $b l s A$ plays a positive role in the virulence of $A$. baumannii due to its global effect on A. baumannii physiology and results finally in increased 
sensitivity of bacteria to the antimicrobial agents [47]. The production of pili which is required for the initial steps of biofilm formation and development of $A$. baumannii, is intermediated by the csuE [48]. Also, AbaI, encoded by $a b a I$, as a quorum-sensing molecule that catalyzes the synthesis of AHL signals, is a required factor for the production of biofilm on abiotic surfaces [49]. In this study, there was a significant downregulation in $a b a I$ and $c s u E$ expression, as well as a considerable upregulation in blsA expression in $A$. baumannii during aPSDT ${ }^{\text {SSR }}$ in comparison with the other groups. On the other hand, the findings show that changes in gene expression were time-dependent. On the 15th day, the highest and lowest changes in gene expression were reported. Our results demonstrated that CurNisNp-aPSDT ${ }^{\text {SSR }}$ could kill bacteria and eliminate $A$. baumannii biofilms, as well as, promote wound healing in mice. Additionally, not only there was no significant difference between CurNisNp-aPS$\mathrm{DT}^{\mathrm{SSR}}$ and SSD groups in anti-biofilm and anti-virulence activities, but also wound healing and re-epithelialization occurred more efficiently in aPSDT ${ }^{\text {SSR }}$ than in the SSD group. Our findings warrant detailed examination of the interactions between the CurNisNp-aPSDT as an alternative therapy for the successful treatment of burn wound infections.

\section{Conclusion}

In conclusion, this in vitro and in vivo study demonstrated that CurNisNp-aPSDT without any cytotoxicity on normal human skin fibroblast cell line could reduce the cell viability of $A$. baumanni via ROS generation. CurNisNp-aPSDT deceased the biofilm growth in $A$. baumannii by altering the expression of genes involved in bacterial pathogenesis and promote wound healing by the acceleration of skin re-epithelialization more than SSD as the standard treatment group. In addition, the results indicated that CurNisNp-aPSDT might be a promising complementary strategy to treat burn wound infections.

\section{Methods}

\section{Synthesis of CurNisNp as the photo-sonosensitizer}

CurNisNp was prepared by the double emulsion-diffusion-evaporation method [8]. Briefly, an equal amount of curcumin and nisin $(5 \mathrm{mg})$ was dissolved in $200 \mu \mathrm{L}$ $1 \%$ polyvinyl alcohol (PVA). $50 \mathrm{mg}$ poly (L-lactic acid) was added to the compound and the mixture was then sonicated at $30 \mathrm{~W}$ for $1 \mathrm{~min}$ to form a primary emulsion. The emulsion was added dropwise to $16 \mathrm{~mL} 2 \%$ PVA and $1 \%$ sucrose. Following the sonication of nanosuspension at $30 \mathrm{~W}, 40 \%$ duty cycle for $3 \mathrm{~min}$, the secondary emulsion was continuously stirred until all the solvents were evaporated. The nanosuspension was centrifuged (at $16,000 \times \mathrm{g}$ for $15 \mathrm{~min}$ ) and then washed three times. $5 \%$ mannitol was added to the nanosuspension and the formulation lyophilized to obtain the dry powder of CurNisNp.

\section{Characterization of CurNisNp}

The surface morphology of CurNisNp was studied by field emission scanning electron microscopy (FESEM; ZEISS, German). The size distribution profiles of nanometer-sized particles, zeta potential, and polydispersity index (PDI) of the CurNisNp were carried out using a MALVERN Zetasizer Ver. 6.01 (Malvern Instruments, UK) at approximately $25^{\circ} \mathrm{C}$. Also, the absorption spectrum of CurNisNp was carried out by a UV-visible spectrophotometer, scanning the absorbance spectra in the range of $350-600 \mathrm{~nm}$ wavelength.

\section{In vitro Cur-Nis release study}

In vitro release study of Cur-Nis from CurNisNp was performed as described by Omobhude et al. [30]. Briefly, $10 \mathrm{mg}$ of CurNisNp was suspended in $10 \mathrm{ml}$ PBS and a homogenous solution was kept on a rotatory shaker at $37^{\circ} \mathrm{C}$ and $200 \times \mathrm{g}$. The samples were collected after centrifugation at $16,000 \times \mathrm{g}$ for $15 \mathrm{~min}$ and the UV-absorbance analysis of supernatant was carried out at various time intervals.

\section{Screening of CurNisNp cytotoxicity by MTT assay, fluorescent staining, and flow cytometry analysis}

The cellular cytotoxicity of the prepared CurNisNp was tested on normal human skin fibroblast cell line (MHFB1; IBRC C11179) as described previously [50]. The cell was purchased from Iranian Biological Resource Center (Tehran, Iran) and grown in the Dulbecco's Modified Eagle Medium/Nutrient Mixture F-12 (DMEM/F12) supplemented with $10 \%$ fetal bovine serum, $2 \mathrm{mML}$-glutamine, $100 \mu \mathrm{g} / \mathrm{mL}$ amphotericin B and $1 \%$ penicillin/ streptomycin antibiotic solution (all purchased from Sigma-Aldrich, Steinheim, Germany) in a humidified environment with $5 \% \mathrm{CO}_{2}$ at $37^{\circ} \mathrm{C}$. MHFB- 1 cells were seeded in 96-well microtiter plates at a density of $2.0 \times 10^{4}$ cells per well. After $24 \mathrm{~h}$, cells were washed with PBS and the highest concentration of CurNisNp $(500 \mu \mathrm{g} /$ $\mathrm{mL}$ ) was added to triplicate wells and kept for $24 \mathrm{~h}$ at $37^{\circ} \mathrm{C}$, with $5 \% \mathrm{CO}_{2} / 95 \%$ air in a humidified incubator. On one of the microtiter plates, a 3- (4,5-dimethylthiazol-2-yl)-2,5-diphenyltetrazolium bromide (MTT) assay kit (Sigma-Aldrich, Steinheim, Germany) was used to evaluate the viability of the cells with a microplate reader at $570 \mathrm{~nm}$ according to the manufacturer's instructions. On another microtiter plate, the cells were resuspended in $100 \mu \mathrm{L}$ binding buffer and incubated with $5 \mu \mathrm{L}$ of 
Annexin V-FITC and propidium iodide (PI) as a counterstain for $15 \mathrm{~min}$ at room temperature, according to the manufacturer's recommendations. Finally, percent of alive cells was evaluated by flow cytometry (Becton Dickinson) and data were analyzed using Flowjo software V7. For detection of alive cells by fluorescent staining, paraformaldehyde (4\% in PBS)-fixed cells were stained with dual acridine orange (AO; $100 \mu \mathrm{g} / \mathrm{mL}$ )/ ethidium bromide (EB; $100 \mu \mathrm{g} / \mathrm{mL}$ ) fluorescent staining solution for $10 \mathrm{~min}$ as described previously [51]. The alive cells were assessed under the fluorescent microscope (OLYMPUS BX53, Japan).

\section{Light source}

The light source used a light-emitting diode (LED, DY400-4, Denjoy, China) at the wavelength of $435 \pm 10 \mathrm{~nm}$ with an output intensity of $1000-1400 \mathrm{~mW} /$ $\mathrm{cm}^{2}$. The medium temperature is stable at room temperature $\left(25 \pm 2{ }^{\circ} \mathrm{C}\right)$.

\section{Ultrasonic irradiation system}

An ultrasound system was used as described previously [13]. The ultrasound parameters employed for treatment purposes were set as follows: a frequency of $1 \mathrm{MHz}$ and pulsed repetition frequency of $100 \mathrm{~Hz}$.

\section{Bacterial strain and growth conditions}

A. baumannii ATCC 29212 strain obtained from Iranian Biological Resource Center has grown aerobically in brain heart infusion (BHI) broth (Laboratorios Conda S.A., Spain) at $37^{\circ} \mathrm{C}$. To examine the antimicrobial efficacy of CurNisNp- based aPSDT, A. baumannii suspension of approximately $1.5 \times 10^{8}$ colony-forming unit $(\mathrm{CFU}) / \mathrm{mL}$ was prepared using both spectrophotometry (optical density [OD] $600 \mathrm{~nm}: 0.08-0.13$ ) and colony counting.

\section{Determination of antimicrobial effects of CurNisNp, LED irradiation, ultrasound waves, and their combination against $A$. baumannii in planktonic growth}

The antimicrobial effects of CurNisNp, LED irradiation, ultrasound waves, and their combination, which would show as $+/+1+,+1+1-,+/-1+,-1+1+,-1+1-$, $-1-1+,+1-1-,-1-1-$ were determined as follows:

\section{Determination of antimicrobial effects of CurNisNp against A. baumannii}

Antimicrobial effect of CurNisNp was determined according to the Clinical and Laboratory Standard Institute (CLSI) guidelines [52]. Briefly, $100 \mu \mathrm{L}$ of Cur$\mathrm{NisNp}$ at a final concentration of $500 \mu \mathrm{g} / \mathrm{mL}$ was diluted as two-fold serial dilutions with $100 \mu \mathrm{L}$ of BHI broth in the wells of a 96 -well microtiter plate. $100 \mu \mathrm{L} /$ well of the A. baumannii $\left(1.5 \times 10^{6} \mathrm{CFU} / \mathrm{mL}\right)$ was added to each well and the microtiter plate was incubated at $37^{\circ} \mathrm{C}$. After $24 \mathrm{~h}, 10 \mu \mathrm{L}$ of each well-containing dilution series were cultured onto BHI agar (Laboratorios Conda S.A., Spain) and $\log _{10}$ CFUs/mL were determined using the previous study [53]. The sub-significant reduction (SSR) dose of CurNisNp (CurNisNp ${ }^{\text {SSR }}$ ) was evaluated based on previous study [54].

\section{Determination of antimicrobial effects of LED against} A. baumannii

Antimicrobial effect of irradiation time of LED against $A$. baumannii was determined according to the previous study [54]. Briefly, $100 \mu \mathrm{L}$ of A. baumannii suspension at the concentration of $1.5 \times 10^{5} \mathrm{CFU} /$ $\mathrm{mL}$ was added to the wells of a 96-well microtiter plate. $A$. baumannii cells were exposed to the LED at the wavelength of $435 \pm 10 \mathrm{~nm}$ with an output intensity of $1000-1400 \mathrm{~mW} / \mathrm{cm}^{2}$ for five variations of time irradiation as following $1,2,3,4$, and 5 min with the energy densities of $60-80,120-168,180-240,252-336$, and $300-420 \mathrm{~J} / \mathrm{cm}^{2}$, respectively. Immediately, $10 \mu \mathrm{L}$ of each well-containing dilution series were cultured onto BHI agar and the plates were incubated at $37^{\circ} \mathrm{C}$ for $24 \mathrm{~h}$. The SSR dose of irradiation time of LED (LED $\left.{ }^{\mathrm{SSR}}\right)$ was then determined as mentioned above.

3. Determination of the antimicrobial effects of ultrasound waves against $A$. baumannii

Antimicrobial effect of ultrasound waves against A. baumannii was done as described previously [13]. Briefly, $100 \mu \mathrm{L}$ of bacterial cells at the concentration of $1.5 \times 10^{5} \mathrm{CFU} / \mathrm{mL}$ in the wells of a 96 -well microtiter plate were exposed to ultrasound waves at a frequency of $1 \mathrm{MHz}$ for $1 \mathrm{~min}$ with five variations of power settings as following 28.7, 36.9, 45.2, 53.4, and $61.6 \mathrm{~mW} /$ $\mathrm{cm}^{2} .10 \mu \mathrm{L}$ of each well-containing dilution series were immediately cultured onto $\mathrm{BHI}$ agar and the agar plates were incubated at $37^{\circ} \mathrm{C}$ for $24 \mathrm{~h}$. The SSR dose of ultrasound intensity (US ${ }^{\mathrm{SSR}}$ ) was determined as described above.

4. Determination of the antimicrobial effects of CurNisNp plus LED irradiation (aPDT) against A. baumannii

To find out the effect of aPDT based on CurNisNp, $100 \mu \mathrm{L}$ of CurNisNp ${ }^{\text {SSR }}$ was added to $100 \mu \mathrm{L} /$ well of the A. baumannii $\left(1.5 \times 10^{6} \mathrm{CFU} / \mathrm{mL}\right)$ in the wells of a 96-well microtiter plate and incubated in the dark 
room $\left(5 \mathrm{~min} ; 25^{\circ} \mathrm{C}\right)$. The treated bacterial suspensions in microtiter plate wells were immediately exposed with the LED at SSR dose of irradiation time. Finally, the $\log _{10}$ CFUs/mL were counted based on the methods mentioned above.

5. Determination of the antimicrobial effects of CurNisNp plus ultrasound waves (aSDT) against A. baumannii

aSDT was done as described previously [36]. Briefy, $100 \mu \mathrm{L}$ of CurNisNp ${ }^{\text {SSR }}$ was added to $100 \mu \mathrm{L} /$ well of the $A$. baumannii $\left(1.5 \times 10^{6} \mathrm{CFU} / \mathrm{mL}\right)$ and the microtiter plate was incubated in the dark room $\left(5 \mathrm{~min} ; 25^{\circ} \mathrm{C}\right)$. After that, the sonication was performed with US ${ }^{\mathrm{SSR}}$. Eventually, the $\log _{10}$ CFUs/mL were counted based on the methods described above.

6. Determination of the antimicrobial effects of ultrasound waves plus LED irradiation against A. baumannii

To determine the antimicrobial response to ultrasound waves plus LED, $200 \mu \mathrm{L}$ of the A. baumannii $\left(1.5 \times 10^{5} \mathrm{CFU} / \mathrm{mL}\right)$ was added to each well and the microtiter plate was incubated in the dark room for $5 \mathrm{~min}$. Then, the wells were exposed with LED $^{\text {SSR }}$ and then $\mathrm{US}^{\mathrm{SSR}}$. Following growth on the BHI agar plates, the $\log _{10}$ CFUs/mL were counted based on the methods mentioned above.

7. Determination of the antimicrobial effects of CurNisNp plus LED irradiation plus ultrasound waves (aPSDT) against $A$. baumannii

$100 \mu \mathrm{L}$ of CurNisNp ${ }^{\text {SSR }}$ was added to the $100 \mu \mathrm{L} /$ well of the $A$. baumannii $\left(1.5 \times 10^{6} \mathrm{CFU} / \mathrm{mL}\right)$ in a 96 -well microtiter plate. After incubation of microtiter plate for $5 \mathrm{~min}$ in the dark room, the bacterial suspension was exposed to $\mathrm{LED}^{\mathrm{SSR}}$ and then immediately $\mathrm{US}^{\mathrm{SSR}}$. The treated $A$. baumannii cells were cultured onto BHI agar and the $\log _{10}$ CFUs/mL were then counted as described above.

\section{Experimental design}

The test groups consisted of $A$. baumannii subjected to:

A. CurNisNp ${ }^{\text {SSR }}$ (CurNisNp at SSR dose)

B. LED ${ }^{\text {SSR }}$ (Irradiation time of light source at SSR dose)

C. US ${ }^{\text {SSR }}$ (Ultrasound intensity at SSR dose)

D. aPDT $^{\text {SSR }}$ (CurNisNp at SSR dose + Irradiation time of light source at SSR dose)

E. aSDT ${ }^{\text {SSR }}$ (CurNisNp at SSR dose + Ultrasound intensity at SSR dose)
F. aPSDT $^{\text {SSR }}$ (CurNisNp at SSR dose + Irradiation time of light source at SSR dose + Ultrasound intensity at SSR)

G. Control (A. baumannii suspension without treatment)

H. Silver sulfadiazine (SSD) $(1 \% \mathrm{w} / \mathrm{w}$ as the standard treatment)

\section{Crystal violet biofilm assay}

Static biofilm formation was assayed in the wells of a 96-well microtiter. Briefly, A. baumannii cells in BHI broth (total volume $300 \mu \mathrm{L}$ ) at the concentration of $1.5 \times 10^{8} \mathrm{CFU} / \mathrm{mL}$ were added to wells of a 96-well microtiter plate and incubated at $37^{\circ} \mathrm{C}$ for $72 \mathrm{~h}$. After treatment of A. baumannii biofilms according to the experimental design described, the biofilms in a 96-well microtiter plate were stained with $0.1 \%$ crystal violet for $20 \mathrm{~min}$, dissolved in 95\% ethanol, and absorbances were measured spectrophotometrically at $570 \mathrm{~nm}$ by a microplate reader (BioTek, Germany). To assess the treatment efficiency of an experimental study on biofilm killing/degradation, the percentage of biofilm killing/degradation was determined as follows:

$$
\text { Biofilm killing/degradation } \%=\frac{\text { OD of untreated slabs }- \text { OD of sample }}{\text { OD of untreated slabs }} \times 100
$$

\section{Measurement of intracellular ROS}

The intracellular ROS was estimated using fluorescent2', $7^{\prime}$-dichlorofluorescein diacetate (DCFHDA) method [55]. Briefly, after centrifugation of the treated A. baumannii cell suspensions at $300 \times \mathrm{g}$ for $30 \mathrm{~min}$, the supernatant was collected and treated with $10 \mu \mathrm{M}$ DCFH-DA for $1 \mathrm{~h}$. The fluorescence intensity of DCF was then quantified with excitation and emission wavelengths of 485 and $530 \mathrm{~nm}$, respectively.

\section{Mouse model of $A$. baumannii-infected burn wound}

All protocols in the animal experiments were approved by the Animal Care Ethics Committee of Tehran University of Medical Sciences (Application no. IR.TUMS. MEDICINE.REC.1399.944). It should be considered that according to the in adherence to international and guidelines for ethical conduct in the care and use of animals [56], in order to observe the ethics of working with experimental animals, after achieving a favorable and acceptable test group in in vitro, the in vivo study was done only in that group.

8 to 12-week-old female BALB/c mice, weighing between $20 \mathrm{~g}$ and $25 \mathrm{~g}$ (Pasteur Institute, Tehran, Iran) were housed in individual cages under sanitary 
conditions with a 12-h light/dark cycle and access to the standardized pellet diet and water ad libitum. Each mouse was anesthetized by an intraperitoneal injection of $2 \%$ xylazine at a dose of $5 \mathrm{mg} / \mathrm{kg}$ and $10 \%$ ketamine at a dose of $100 \mathrm{mg} / \mathrm{kg}$. The dorsal skin of the mice was shaved $(3 \mathrm{~cm} \times 4 \mathrm{~cm})$ with an electric razor and cleaned with povidone-iodine (10\%) and ethanol (70\%). As described our previous study [48], a full-thickness, third-degree burn model was prepared. A $50 \mu \mathrm{L}$ suspension of $A$. baumannii $\left(1.5 \times 10^{8} \mathrm{CFU} / \mathrm{mL}\right)$ was dripped into each wound. The wound was fixed with sterile gauze, and the mice were housed in individual cages. As previously reported [47], the duration from inoculation to successful modeling is $24 \mathrm{~h}$. Eight mice were then treated by aPSDT at SSR doses of CurNisNp, irradiation time of LED, and ultrasound intensity after induction of A. baumannii, eight mice were treated by SSD, and the other burned mice served as controls $(n=4)$ and received physiological saline instead of any therapeutic treatment. The aPSDT ${ }^{\text {SSR }}$ and SSD treatment were done completely in the darkroom and repeated for up to 15 days.

\section{Evaluation of wound healing potential}

The progressive changes of burned area were photographed every 5 days and analyzed using size analysis Software-Image J. The percentage of the wound contracture rate was determined according to the following formula:

$$
\% \text { Rate of contracture }=\frac{\text { Specific day wound size }}{\text { Initial wound size }} \times 100
$$

\section{Counting of bacteria on wounds}

The number of bacteria on the wound surface before (day 0 ) and on the 1st, 5 th, 10th, and 15th days after aPSDT ${ }^{\text {SSR }}$ and SSD were measured. At each time point, a part of each ulcer ( $5 \mathrm{~mm}$ in diameter) was cut aseptically using punch biopsy forceps. These specimens were homogenized in $1 \mathrm{~mL}$ of sterile saline and the viable bacteria counted as described above.

\section{Assessment of the virulence-associated genes expression by quantitative real-time PCR}

The residual suspensions of treated wound samples were used for RNA extraction. The total RNA extraction was performed using the GeneAll Hybrid-R RNA purification kit (Seoul, Korea) according to the manufacturer's recommendations. The elimination of genomic DNA and cDNA synthesis were done by RNase-free DNase I treatment and RevertAid First Strand cDNA Synthesis
Kit, respectively (both purchased from Thermo Scientific $\mathrm{GmbH}$, Germany). The nucleotide sequences of primers for quantitative real-time PCR as described in Table 2. A housekeeping gene (16S rRNA) as the most stable gene was used for the normalization of the reactions. Reaction plates were processed under the following conditions: an initial denaturation of $5 \mathrm{~min}$ at $95^{\circ} \mathrm{C}$, followed by 35 cycles of $95^{\circ} \mathrm{C}$ for $15 \mathrm{~s}$, annealing for $10 \mathrm{~s}$ at $60^{\circ} \mathrm{C}$, and $72^{\circ} \mathrm{C}$ for $10 \mathrm{~s}$. Fold differences in RNA expression were calculated by the $2^{-\Delta \Delta C t}$ method using the Relative Expression Software Tool (REST) 2009 software (version 2.0.13; Qiagen, Valencia, CA, USA), and the changes greater than or equal to two-fold were considered significant [57].

\section{Histopathological examinations of burn wound infections}

The tissues cross-sections $(5-10 \mathrm{~mm})$ from each wound obtained on the 1st, 5th, 10th, and 15th days after aPSDT $^{\text {SSR }}$ and SSD were processed for histopathological study. Tissue samples were fixed in $10 \%$ buffered formalin in PBS for $72 \mathrm{~h}$. Paraffin-embedded tissue sections of $3-5 \mu \mathrm{m}$ thick were prepared and stained with hematoxylin-eosin (HE). A general optical microscope (Olympus, Tokyo, Japan) was used to assess the inflammation, fibroblasts, blood vessels, and re-epithelialization.

\section{Statistical analysis}

All experiments were repeated five times. The data of quantitative variables were presented as the median, interquartile range $(\mathrm{IQR})$, and mean \pm standard deviation $(\mathrm{SD})$ based on the studies of Pérez-Granda et al. [58] and Alonso et al. [59]. Data were evaluated using one-way analysis of variance (ANOVA) and values $P<0.05$ were considered statistically significant.

Table 2 Primer sequences used in this study

\begin{tabular}{|c|c|c|c|}
\hline Genes & & Sequences $\left(5^{\prime}-3\right)^{a}$ & $\begin{array}{l}\text { Amplicon } \\
\text { Size (bp) }\end{array}$ \\
\hline \multirow[t]{2}{*}{ csuE } & $\mathrm{F}$ & AGTGTATCGCCGGGTGTTTA & 113 \\
\hline & $\mathrm{R}$ & AACCCAGGGCTCTCAAAGAA & \\
\hline \multirow[t]{2}{*}{$b / s A$} & $\mathrm{~F}$ & ACCTTTAACCCGCTTTTGCT & 117 \\
\hline & $\mathrm{R}$ & TCCCCTATTCACCATTCCAA & \\
\hline \multirow[t]{2}{*}{$a b a l$} & $\mathrm{~F}$ & TACCCACCACACAACCCTATTT & 126 \\
\hline & $\mathrm{R}$ & GCGGTTTTGAAAAATCTACGGC & \\
\hline \multirow[t]{2}{*}{$16 S r R N A$} & $\mathrm{~F}$ & AAAGTTGGTATTCGCAACGG & 117 \\
\hline & $\mathrm{R}$ & ACCTTTAACCCGCTTTTGCT & \\
\hline
\end{tabular}




\section{Abbreviations}

aPDT: Antimicrobial photodynamic therapy; aSDT: Antimicrobial sonodynamic therapy; aPSDT: Antimicrobial photo-sonodynamic therapy; Cur: Curcumin; Nis: Nisin; ROS: Reactive oxygen species; SSD: Silver sulfadiazine; SSR: Subsignificant reduction.

\section{Acknowledgements}

We thank the staff of BioHealth Laboratory and Dr. Reza Mousavi for histological staining and expert interpretation of slides.

\section{Authors' contributions}

M.P. designed the experiments, performed the experiments, analyzed the data, authored or reviewed drafts of the paper, prepared figures and/or tables, and approved the final draft. A.B. conceived and designed the experiments, analyzed the data, authored or reviewed drafts of the paper, and approved the final draft. All authors reviewed the manuscript. The authors read and approved the final manuscript.

\section{Funding}

This research was supported by Tehran University of Medical Science and Health Services Grant No. 1399-4-45939.

\section{Availability of data and materials}

All data of this manuscript are included in the manuscript. All figures are original images and have been used for the first time in this study. Any additional information required will be provided by communicating with the corresponding author via the official mail: abahador@sina.tums.ac.ir.

\section{Declarations}

\section{Ethics approval and consent to participate}

All protocols in the animal experiments were approved by the Animal Care Ethics Committee of Tehran University of Medical Sciences (Application no. IR.TUMS.MEDICINE.REC.1399.944). All methods were carried out in in adherence to international and guidelines for ethical conduct in the care and use of animals. The study was carried out in compliance with the ARRIVE guidelines.

\section{Consent for publication}

Not applicable.

\section{Competing interests}

The authors declare no conflicts of interest.

\section{Author details}

${ }^{1}$ Dental Research Center, Dentistry Research Institute, Tehran University of Medical Sciences, Tehran, Iran. ${ }^{2}$ Pediatric Infectious Disease Research Center, Tehran University of Medical Sciences, Tehran, Iran. ${ }^{3}$ Pediatrics Center of Excellence, Children's Medical Center, Tehran University of Medical Sciences, Tehran, Iran. ${ }^{4}$ Department of Microbiology, School of Medicine, Tehran University of Medical Sciences, Tehran, Iran. ${ }^{5}$ Fellowship in Clinical Laboratory Sciences, BioHealth Lab, Tehran, Iran.

Received: 31 July 2021 Accepted: 7 January 2022

Published online: 17 January 2022

\section{References}

1. Church D, Elsayed S, Reid O, Winston B, Lindsay R. Burn wound infections. Clin Microbiol Rev. 2006;19(2):403-34.

2. Vinaik R, Barayan D, Shahrokhi S, Jeschke MG. Management and prevention of drug resistant infections in burn patients. Expert Rev Anti-Infect Ther. 2019;17(8):607-19.

3. Asati $S$, Chaudhary U. Prevalence of biofilm producing aerobic bacterial isolates in burn wound infections at a tertiary care hospital in northern India. Ann Burns Fire Disasters. 2017;30(1):39.

4. Yang CH, Su PW, Moi SH, Chuang LY. Biofilm formation in Acinetobacter Baumannii: genotype-phenotype correlation. Molecules. 2019;24(10):1849.
5. Golberg A, Broelsch GF, Vecchio D, Khan S, Hamblin MR, Austen WG Jr, et al. Eradication of multidrug-resistant A. baumannii in burn wounds by antiseptic pulsed electric field. Technology (Singap World Sci). 2014;2(2):153-60.

6. Khan A, Xu M, Wang T, You C, Wang X, Ren H, et al. Catechol cross-linked antimicrobial peptide hydrogels prevent multidrug-resistant Acinetobacter baumannii infection in burn wounds. Biosci Rep. 2019;39(6):1-5.

7. Pourhajibagher M, Boluki E, Chiniforush N, Pourakbari B, Farshadzadeh Z, Ghorbanzadeh R, et al. Modulation of virulence in Acinetobacter baumannii cells surviving photodynamic treatment with toluidine blue. Photodiagn Photodyn Ther. 2016;15:202-12.

8. Nabofa WE, Alashe OO, Oyeyemi OT, Attah AF, Oyagbemi AA, Omobowale TO, et al. Cardioprotective effects of curcumin-nisin based poly lactic acid nanoparticle on myocardial infarction in guinea pigs. Sci Rep. 2018:8(1):1-1.

9. Shin JM, Gwak JW, Kamarajan P, Fenno JC, Rickard AH, Kapila YL. Biomedical applications of nisin. J Appl Microbiol. 2016;120(6):1449-65.

10. Kocaadam B, Şanlier N. Curcumin, an active component of turmeric (Curcuma longa), and its effects on health. Crit Rev Food Sci Nutr. 2017:57(13):2889-95.

11. Jakubczyk K, Drużga A, Katarzyna J, Skonieczna-Żydecka K. Antioxidant potential of curcumin - a Meta-analysis of randomized clinical trials. Antioxidants. 2020;9(11):1-13.

12. Aziziaram Z, Bilal I, Zhong Y, Mahmod AK, Roshandel MR. Protective effects of curcumin against naproxen-induced mitochondrial dysfunction in rat kidney tissue. Cell Mole Biomed Rep. 2021;1(1):23-32.

13. Pourhajibagher M, Rahimi Esboei B, Hodjat M, Bahador A. Sonodynamic excitation of nanomicelle curcumin for eradication of Streptococcus mutans under sonodynamic antimicrobial chemotherapy: enhanced anti-caries activity of nanomicelle curcumin. Photodiagn Photodyn Ther. 2020;30:101780.

14. Kumari A, Yadav SK, Yadav SC. Biodegradable polymeric nanoparticles based drug delivery systems. Colloids Surf B Biointerfaces. 2010;75(1):1-18.

15. Fan L, Muhammad Al, Ismail BB, Liu D. Sonodynamic antimicrobial chemotherapy: An emerging alternative strategy for microbial inactivation. Ultrason Sonochem. 2021;75:105591.

16. Kayani Z, Dehdari Vais R, Soratijahromi E, Mohammadi S, Sattarahmady N. Curcumin-gold-polyethylene glycol nanoparticles as a nanosensitizer for photothermal and sonodynamic therapies: in vitro and animal model studies. Photodiagn Photodyn Ther. 2021;33:102139.

17. Pourhajibagher M, Bahador A. In vitro application of Sonodynamic antimicrobial chemotherapy as a Sonobactericidal therapeutic approach for bacterial infections: a systematic review and Meta-analysis. J Lasers Med Sci. 2020;11(1):1-7.

18. Alves F, Gomes Guimarães G, Mayumi Inada N, Pratavieira S, Salvador Bagnato V, Kurachi C. Strategies to Improve the Antimicrobial Efficacy of Photodynamic, Sonodynamic, and Sonophotodynamic Therapies. Lasers Surg Med. 2021;53:1113-21 [ahead of print].

19. Cusicanqui Méndez DA, Cardenas Cuéllar MR, Pedrinha VF, Velásquez Espedilla EG, de Andrade FB, Rodrigues PA, et al. Effects of curcuminmediated antimicrobial photodynamic therapy associated to different chelators against enterococcus faecalis biofilms. Photodiagn Photodyn Ther. 2021;35:102464.

20. Garrier J, Bezdetnaya L, Barlier C, Grafe S, Guillemin F, D'Hallewin MA. Foslip (R)-based photodynamic therapy as ameans to improve wound healing. Photodiagn Photodyn Ther. 2011;8(4):321-7.

21. Rosa LP, da Silva FC, Vieira RL, et al. Application of photody-namic therapy, laser therapy, and a cellulose membrane forcalcaneal pressure ulcer treatment in a diabetic patient: a casereport. Photodiagn Photodyn Ther. 2017;19:235-8.

22. Mahmoudi H, Pourhajibagher M, Alikhani MY, Bahador A. The effect of antimicrobial photodynamic therapy on the expression of biofilm associated genes in staphylococcus aureusstrains isolated from wound infections in burn patients. Photodiagn Photodyn Ther. 2019;25:406-13.

23. Mosti G, Picerni P, Licau M, Mattaliano V. Photodynamic therapy in infected venous and mixed leg ulcers: a pilot experience. J Wound Care. 2018;27(12):816-21.

24. Sun Y, Ogawa R, Xiao BH, Feng YX, Wu Y, Chen LH, et al. Antimicrobial photodynamic therapy in skin wound healing: a systematic review of animal studies. Int Wound J. 2020;17(2):285-99. 
25. Yang Y, Tu J, Yang D, Raymond JL, Roy RA, Zhang D. Photo- and Sonodynamic therapy: a review of mechanisms and considerations for pharmacological agents used in therapy incorporating light and sound. Curr Pharm Des. 2019;25(4):401-12.

26. Liu X, Gan H, Hu C, Sun W, Zhu X, Meng Z, et al. Silver sulfadiazine nanosuspension-loaded thermosensitive hydrogel as a topical antibacterial agent. Int J Nanomedicine. 2019;14:289-300.

27. Cartotto R. Topical antimicrobial agents for pediatric burns. Burns Trauma. 2017:5:33-8.

28. Pang X, Li D, Zhu J, Cheng J, Liu G. Beyond antibiotics: photo/ Sonodynamic approaches for bacterial Theranostics. Nanomicro Lett. 2020;12(1):144.

29. Li G, Zhao M, Xu F, Yang B, Li X, Meng X, et al. Synthesis and biological application of Polylactic acid. Molecules. 2020;25(21):5023.

30. Omobhude ME, Morenikeji OA, Oyeyemi OT. Molluscicidal activities of curcumin-nisin polylactic acid nanoparticle on Biomphalaria pfeifferi. PLoS NegI Trop Dis. 2017;11(8):e0005855.

31. Longo F, Vuotto C, Donelli G. Biofilm formation in Acinetobacter baumannii. New Microbiol. 2014;37(2):119-27.

32. Harding CM, Hennon SW, Feldman MF. Uncovering the mechanisms of Acinetobacter baumannii virulence. Nat Rev Microbiol. 2018;16(2):91-102.

33. Pourhajibagher M, Rokn AR, Barikani HR, Bahador A. Photo-sonodynamic antimicrobial chemotherapy via chitosan nanoparticles-indocyanine green against polymicrobial periopathogenic biofilms: ex vivo study on dental implants. Photodiagn Photodyn Ther. 2020;31:101834.

34. Su K, Tan L, Liu X, Cui Z, Zheng Y, Li B, et al. Rapid photo-Sonotherapy for clinical treatment of bacterial infected bone implants by creating oxygen deficiency using sulfur doping. ACS Nano. 2020;14(2):2077-89.

35. Vanerio N, Stijnen M, de Mol BAJM, Kock LM. Biomedical applications of photo- and Sono-activated rose Bengal: a review. Photobiomodul Photomed Laser Surg. 2019;37(7):383-94.

36. Pourhajibagher $M$, Bahador A. Attenuation of Aggregatibacter actinomycetemcomitans virulence using curcumin-decorated nanophytosomes-mediated photo-sonoantimicrobial chemotherapy. Sci Rep. 2021;11(1):6012

37. Xu F, Hu M, Liu C, Choi SK. Yolk-structured multifunctional up-conversion nanoparticles for synergistic photodynamicsonodynamic antibacterial resistance therapy. Biomater Sci. 2017;5(4):678-85.

38. Yang W, Yoon Y, Lee Y, Oh H, Choi J, Shin S, et al. Photosensitizer-peptoid conjugates for photoinactivation of gram-negative bacteria: structureactivity relationship and mechanistic studies. Org Biomol Chem. 2021;19(29):6546-57.

39. Zhang Y, Yang C, Yang D, Shao Z, Hu Y, Chen J, et al. Reduction of graphene oxide quantum dots to enhance the yield of reactive oxygen species for photodynamic therapy. Phys Chem Chem Phys. 2018;20(25):17262-7.

40. Hamblin MR. Potentiation of antimicrobial photodynamic inactivation by inorganic salts. Expert Rev Anti-Infect Ther. 2017;11:1059-69.

41. Dharmaraja AT. Role of reactive oxygen species (ROS) in therapeutics and drug resistance in Cancer and Bacteria. J Med Chem. 2017:60(8):3221-40.

42. Ming L, Cheng K, Chen Y, Yang R, Chen D. Enhancement of tumor lethality of ROS in photodynamic therapy. Cancer Med. 2021;10(1):257-68.

43. Jiang C, Yang W, Wang C, Qin W, Ming J, Zhang M, et al. Methylene bluemediated photodynamic therapy induces macrophage apoptosis via ROS and Reduces bone resorption in periodontitis. Oxidative Med Cell Longev. 2019;2019:1529520.

44. An J, Hu YG, Cheng K, Li C, Hou XL, Wang GL, et al. ROS-augmented and tumor-microenvironment responsive biodegradable nanoplatform for enhancing chemo-sonodynamic therapy. Biomaterials. 2020;234:119761.

45. You DG, Deepagan VG, Um W, Jeon S, Son S, Chang H, et al. ROS-generating $\mathrm{TiO} 2$ nanoparticles for non-invasive sonodynamic therapy of cancer. Sci Rep. 2016;6:23200.

46. Eze EC, Chenia HY, El Zowalaty ME. Acinetobacter baumannii biofilms: effects of physicochemical factors, virulence, antibiotic resistance determinants, gene regulation, and future antimicrobial treatments. Infect Drug Resist. 2018;11:2277-99.

47. Bahador A, Farshadzadeh Z, Raoofian R, Mokhtaran M, Pourakbari B, Pourhajibagher $M$, et al. Association of virulence gene expression with colistin-resistance in Acinetobacter baumannii: analysis of genotype, antimicrobial susceptibility, and biofilm formation. Ann Clin Microbiol Antimicrob. 2018;17(1):24-30.

48. Colquhoun JM, Rather PN. Insights into mechanisms of biofilm formation in Acinetobacter baumannii and implications for Uropathogenesis. Front Cell Infect Microbiol. 2020;10:253-9.

49. Sun X, Ni Z, Tang J, Ding Y, Wang X, Li F. The abal/abaR quorum sensing system effects on pathogenicity in Acinetobacter baumannii. Front Microbiol. 2021;12:679241.

50. Pourhajibagher M, Partoazar A, Alaeddini M, Etemad-Moghadam S, Bahador A. Photodisinfection effects of silver sulfadiazine nanoliposomes doped-curcumin on Acinetobacter baumannii: a mouse model. Nanomedicine (Lond). 2020;15(5):437-52.

51. Pourhajibagher M, Azimi M, Haddadi-AsI V, Ahmadi H, Gholamzad M, Ghorbanpour S, et al. Robust antimicrobial photodynamic therapy with curcumin-poly (lactic-co-glycolic acid) nanoparticles against COVID-19: a preliminary in vitro study in Vero cell line as a model. Photodiagn Photodyn Ther. 2021;34:102286

52. CLSI, Methods for dilution antimicrobial susceptibility tests for Bacteria that grow aerobically; approved standard-tenth edition, clinical and laboratory standards institute, Wayne, PA, M100Ed29E, 2019.

53. Luca L, Oroian M. Influence of different prebiotics on viability of lactobacillus casei, lactobacillus plantarum and lactobacillus rhamnosus encapsulated in alginate microcapsules. Foods. 2021;10(4):710.

54. Pourhajibagher M, Beytollahi L, Ghorbanzadeh R, Bahador A. Analysis of glucosyltransferase gene expression of clinical isolates of Streptococcus mutans obtained from dental plaques in response to sub-lethal doses of photoactivated disinfection. Photodiagn Photodyn Ther. 2018;24:75-81.

55. Zhang XF, Shen W, Gurunathan S. Biologically synthesized gold nanoparticles ameliorate cold and heat stress-induced oxidative stress in Escherichia coli. Molecules. 2016;21(6):1-18.

56. American Psychological Association (APA). Guidlines for ethical conduct in the care and use of nonhuman animals in research. 2014. www.apa. org/science/leadership/care/guidelines

57. Livak KJ, Schmittgen TD. Analysis of relative gene expression data using real-time quantitative $P C R$ and the $2-\triangle \triangle C T$ method. Methods. 2001:25:402-8.

58. Pérez-Granda MJ, Latorre MC, Alonso B, Hortal J, Samaniego R, Bouza E, et al. Eradication of P. aeruginosa biofilm in endotracheal tubes based on lock therapy: results from an in vitro study. BMC Infect Dis. 2017;17(1):1-6.

59. Alonso B, Pérez-Granda MJ, Latorre MC, Sánchez-Carrillo C, Bouza E, Muñoz P, et al. Production of biofilm by Staphylococcus aureus: Association with infective endocarditis? Enfermedades Infecciosas y Microbiología Clínica. 2021;S0213-005X(21):00081 [ahead of print]

\section{Publisher's Note}

Springer Nature remains neutral with regard to jurisdictional claims in published maps and institutional affiliations.

Ready to submit your research? Choose BMC and benefit from:

- fast, convenient online submission

- thorough peer review by experienced researchers in your field

- rapid publication on acceptance

- support for research data, including large and complex data types

- gold Open Access which fosters wider collaboration and increased citations

- maximum visibility for your research: over 100M website views per year

At BMC, research is always in progress.

Learn more biomedcentral.com/submissions 